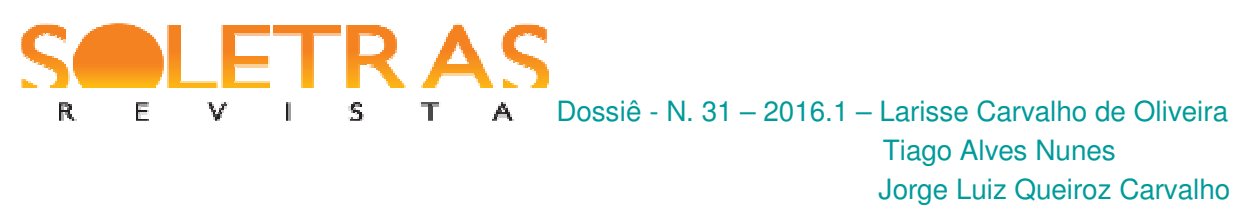

\title{
Verbos modais como estratégia linguístico-discursiva de (im) polidez linguística e preservação de faces nas interações médico-médico e médico- paciente da série House
}

\author{
Jorge Luis Queiroz Carvalho ${ }^{1}$ \\ Larisse Carvalho de Oliveira $^{2}$ \\ Tiago Alves Nunes ${ }^{3}$
}

Secretaria da Educação Básica do Ceará

\begin{abstract}
Resumo: A polidez linguística ancora a construção, manutenção e preservação de faces dos interlocutores, de sorte que o monitoramento da produção de eventos comunicativos é primordial nesses processos. O objetivo do presente estudo é analisar as estratégias de (im)polidez e preservação de faces em diálogos entre os personagens médicos da série televisiva House (2004-2012) e pacientes, atentando para o fato de que tais estratégias fazem parte da construção discursiva dos artefatos linguísticos típicos dessa profissão. Como suporte teórico, usamos os estudos de Brown e Levinson (1987), Goffman (1967) e Paiva (2008), no que diz respeito aos conceitos de polidez positiva, negativa e preservação de faces. Primeiramente, escolhemos doze episódios da série citada, coletamos os scripts na língua original do programa (inglês) através de consulta a páginas da internet e conferimos a transcrição com o áudio. Em seguida, separamos os diálogos em que havia interações entre pacientes e médicos para avaliar como os verbos modais poderiam colaborar, ou não, para o processo de polidez e preservação da imagem/face de seus interlocutores. As ocorrências analisadas mostraram que os médicos participantes da equipe do Dr. House buscaram preservar sua face através do uso de verbos modais e da inclusão de suas figuras nos enunciados. Como fator mitigador de responsabilidade ou diminuição da força ilocucionária de seus atos de fala, tais profissionais funcionaram como fonte e alvo de seus enunciados. Portanto, podemos concluir que o uso de tais verbos viabilizou a redução do peso da responsabilidade e de atos ameaçadores de face nas interações sociais representadas pela série.
\end{abstract}

Palavras-chave: Interação. Preservação das Faces. Polidez Linguística. Modalidade.

\section{Introdução}

1 Mestre em Linguística pelo Programa de Pós-graduação em Linguística da Universidade Federal do Ceará (PPGL/UFC). Graduado em Letras Inglês e suas respectivas Literaturas pela Universidade do Estado do Rio Grande do Norte (UERN). É professor de Língua Inglesa da Secretaria da Educação Básica do Ceará (SEDUCCE).

2 Mestra em Linguística pelo Programa de Pós-graduação em Linguística da Universidade Federal do Ceará (PPGL/UFC). Graduada em Letras Português/Inglês e suas respectivas Literaturas pela mesma instituição. É professora de Língua Inglesa da Secretaria da Educação Básica do Ceará (SEDUC-CE).

3 Mestre em Linguística pelo Programa de Pós-graduação em Linguística da Universidade Federal do Ceará (PPGL/UFC). Graduado em Letras Português/Espanhol e suas respectivas Literaturas pela mesma instituição. É professor de Língua Portuguesa da Secretaria da Educação Básica do Ceará (SEDUC-CE). 
Nas interações discursivas, em especial as que envolvem um maior monitoramento na produção de eventos comunicativos, tais como naquelas que se manifestam por meio de gêneros dialogais como entrevistas, conversas cotidianas, consultas médicas e demais interlocuções face a face, as estratégias de polidez linguística podem ser vistas como fenômenos significativamente recorrentes, tanto na construção quanto na preservação da face do enunciador e do coenunciador. As estratégias que estabelecem esses fenômenos são determinadas socialmente e são necessárias para um entendimento mútuo. Portanto, compreender e ser compreendido com o menor número de problemas na comunicação é um fator indispensável para a compreensão e pode ser alcançado através dos eventos da polidez.

Nesta investigação, analisamos as estratégias de (im)polidez linguística e de preservação de faces nas interações entre personagens da série televisiva americana House (2004-2012). Com esse exercício de análise, pretendemos notar como a polidez faz parte das estratégias discursivas dos médicos e pode ser marcada linguisticamente por expressões de modalidade, em especial a deôntica. Diante da lacuna de estudos que articulem a noção de polidez com a de modalização, focamos em como a categoria de análise dos verbos modais de valor deôntico é convocada no processo de polidez linguística e, assim, a preservação de faces. Temos como objetivo central, portanto, averiguar como esses itens linguísticodiscursivos podem colaborar, ou não, para a preservação de faces bem como para marcação da (im)polidez.

Nas próximas seções, portanto, abordamos os principais conceitos através dos quais este estudo é orientado, quais sejam: polidez linguística, face (BROWN \& LEVINSON, 1987) e modalidade (LYONS, 1977; LOPES, 2009, 2012; OLIVEIRA, 2016). Na sequência, apresentamos a metodologia que seguimos para lograr os objetivos pretendidos e, adiante, o exercício analítico, com discussões e resultados.

\section{Sobre a teoria de preservação de faces e as estratégias de polidez linguística: breves conceituações}

O conceito de face foi instituído por Goffman (1967) que concebeu essa noção para se referir à autoimagem que um dado enunciador cria para se afirmar socialmente. Nessa perspectiva, toda interação social - entre membros adultos de uma dada comunidade pressupõe falantes que constroem e mantêm uma face, ou seja, uma imagem pública.

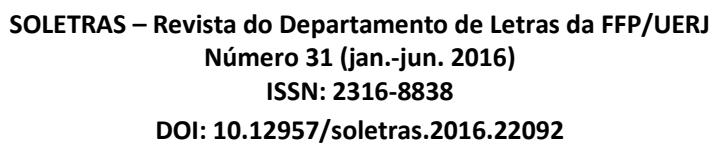




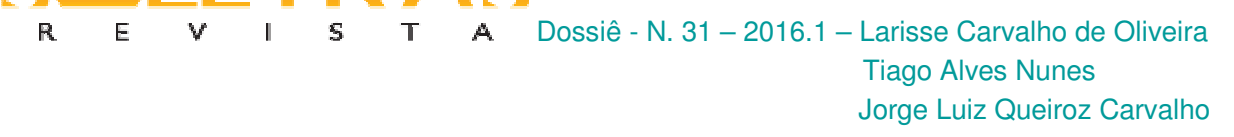

Enquanto atores sociais, objetivamos criar representações do quanto somos dignos de respeito e/ou mostrar que consideramos outros parceiros da troca verbal merecedores desse mesmo valor. No entanto, considerando que as interações sociais são práticas simbólicas, ritualizadas e, justamente por isso, processuais, as faces precisam ser preservadas para que essa imagem não seja ameaçada e, assim, desconstruída nas situações de comunicação.

Dentro desse contexto, fala-se em face positiva e face negativa. Enquanto aquela é o conjunto de características do enunciador (imagens valorizadas socialmente) que este deseja mostrar, ou impor, numa interação, esta diz respeito aos aspectos que deseja preservar, ocultar, uma vez que pertencem ao território do "eu". Portanto, numa interação, os enunciadores tentam sempre preservar sua face negativa, ao mesmo tempo que mostram sua face positiva, daí que, num processo interativo, em especial a conversação, é constante o risco de ameaça (à face), em especial pelos chamados atos ameaçadores de face, sobre os quais comentamos a seguir.

Alguns atos ameaçadores de face, por exemplo, podem causar danos a uma imagem previamente estabelecida a partir de, pelo menos, três tipos de ofensas, a saber: i) ofensas inocentes: gafes, constrangimentos ou qualquer tipo de insulto que não tenha sido intencional; ii) ofensas maliciosas: críticas destrutivas, ataques, escárnios; iii) ofensas incidentais: quando também não há intenção, mas a ação gera uma consequência negativa. Para Brown e Levinson (1987), esses atos devem ser entendidos como ações verbais e não necessariamente materiais, como agressões e violência física, ou seja, as ameaças à face podem se manifestar linguisticamente e são estabelecidas socialmente, por meio de insultos, críticas e censuras.

Diante dessas ameaças, as faces estão sempre na iminência de serem protegidas, isto é, os interlocutores monitoram, constantemente, seus eventos comunicativos. Por isso, é preciso destacar que cada sociedade elabora um conjunto de práticas que podem atuar na preservação de faces. Goffman (1967), pensando em estratégias comuns no mundo ocidental, propõe três movimentos que auxiliam a manutenção e a preservação das imagens dos enunciadores: i) o processo de distanciamento: cuja finalidade é prevenir que a face seja ameaçada, diz respeito a uma série de medidas protetivas que o enunciador toma para se afastar daquilo que pode ferir sua face; ii) o processo corretivo: diferentemente do anterior, não visa prevenção de ataques à face, mas corrigir os atos de ameaça que já foram postos em práticas; iii) 
intermudança: quando a preservação acontece a partir de uma sequência de atos que visa restabelecer a face agredida (desafio, oferta, aceitação da oferta e perdão).

As estratégias de polidez linguística, por sua vez, têm destaque nas pesquisas de Brown e Levinson (1987) e estão incluídos nos estudos da Sociolinguística Interacional. O enunciador, através de algumas estratégias, tenta preservar sua face e a do coenunciador justamente para evitar os atos ameaçadores. No entanto, pode acontecer de a tentativa de preservação não suceder, se for desejo dos enunciadores.

Brown e Levinson (1987) reconfiguram o conceito de face de Goffman (1967), evidenciando que esta pode ser mantida, intensificada ou perdida; o uso, ou não, das estratégias de preservação orientam o que ocorrerá com a face, isso porque a dita preservação está imbricada à emoção, uma vez que o maior ou menor afeto que se tem pelo interactante com quem se desenvolve a interação, orientará o grau de estratégia escolhida, do menor grau ao maior ameaçador de face. Se o interactante perder sua face (losing face), este pode ficar em uma situação humilhante, embaraçosa; assim, ele terá de, usando estratégias, recuperar, reconstruir/restabelecer sua face. A necessidade de manter a face configura a existência dos atos ameaçadores de face, como já citado.

Ao ter a face ameaçada, mesmo em uma interação corriqueira, cotidiana, em termos de polidez, o interactante pode escolher os tipos seguintes de estratégias para manter sua face: estratégias on record, que fazem com que o falante se comprometa com o dito; off record, estratégias pelas quais o falante evita se comprometer com o dito; e, por fim, as bald on record, pelas quais ao falante não importa como o dizer será enunciado, e, sim, lança sua atenção ao conteúdo do dizer.

A seguir, tratamos do conceito de modalidade bem como de sua relação com as estratégias de polidez linguística e preservação de faces.

\section{Sobre a modalidade e a sua vertente deôntica}

$\mathrm{Na}$ antiguidade clássica, Aristóteles se ocupou do estudo da lógica para tentar explicar o raciocínio empreendido pelo homem, abrindo caminho para as definições de modalidade mais associadas ao estudo filosófico e da lógica. A modalidade denominada alética, ou aristotélica, está relacionada ao conceito de verdade e falsidade de proposições. Em Lyons (1977, p. 791), 


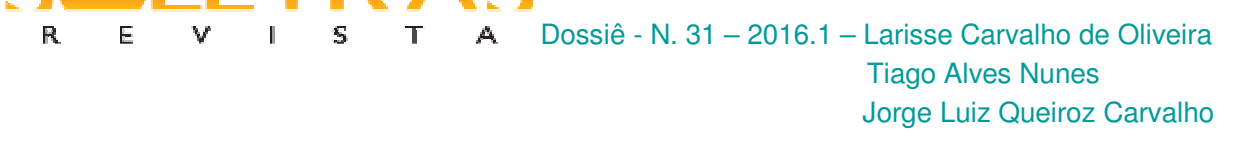

há que o termo "alético" tem relações com o vocábulo grego que significa "verdade", ou seja, para o autor, "todas as proposições aleticamente necessárias são aleticamente possíveis, mas não vice-versa" (LYONS, 1997, p. 791) ${ }^{4}$. Já Cervoni (1989, p. 59) atesta que "as modalidades fundamentais são aquelas que concernem à verdade do conteúdo das proposições”. Tal afirmação deve levar em consideração os variados sentidos que as diferentes modalidades podem infligir aos enunciados de seus falantes a depender do contexto de sua ocorrência.

Koch (2004, p. 73), por sua vez, pondera que as modalidades são "como parte da atividade ilocucionária, já que revelam a atitude do falante perante o enunciado que produz". Assim, o falante é consciente da força ilocucionária que impõe em cada enunciado que emite. A autora ressalta, ainda, que, posteriormente, os valores de necessidade e possibilidade foram agrupados aos tipos deôntico e epistêmico de modalidade, respectivamente. Na comunicação, os falantes estruturam seu discurso, e, conforme a autora, "a relação entre enunciados é frequentemente projetada a partir de certas relações de modalidade, donde se depreende a sua importância pragmática" (KOCH, 2004, p.74). Desta forma, os preceitos do uso e do contexto comunicativo bem como interacional são pregados pelos estudos da modalidade, sublinhando a importância das relações/interações entre falantes e ouvintes.

Lyons (1977) aborda as modalidades de necessidade lógica e de possibilidade lógica, que se relacionam às vertentes deôntica e epistêmica. A primeira diz respeito à função instrumental da linguagem que, de um lado, expressa ou indica o querer e o desejo e, de outro, faz com que as "coisas aconteçam" por meio da imposição da intenção, do desejo e da vontade de seus agentes, relacionando-se aos eixos do obrigatório, do proibido e do permitido. A epistêmica, por sua vez, trata do conhecimento do falante para com a verdade do seu enunciado, influenciando o que é dito, como se, em mundos alternativos, o falante tivesse várias possibilidades de enunciações, variando, essas, frente ao grau de vinculação ao que é tratado pelo falante.

De acordo com Oliveira (2014, p. 697), a modalidade deôntica configura "maior carga semântica aos modais, transportando o teor volitivo de sua fonte para com seu alvo, por vezes mitigando ou asseverando aquilo exposto. " Isto significa que a fonte, aquele que emite um

4 Tradução nossa, texto original: "All alethically necessary propositions are alethically possible, but not conversely." 


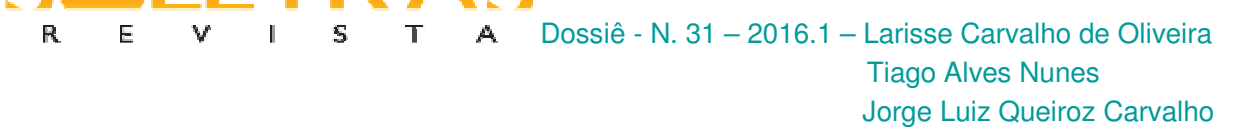

enunciado deôntico, poderá incluir-se, ou não, como alvo (locutor) do mesmo enunciado para “abrandar" o valor - permissão, obrigação, proibição - que foi utilizado.

Em nossa análise, a qual será apresentada posteriormente, buscamos relacionar os valores de permissão e obrigação deônticos, da categoria gramatical da modalidade, com as estratégias de polidez e preservação de face para demonstrar como os personagens da série House minimizam a força ilocucionária de seus enunciados, preservando, assim, suas faces e, por vezes, ameaçando a do coenunciador.

\section{Metodologia}

O corpus escolhido foi abstraído do universo das séries televisivas, em especial, de séries médicas. Tais manifestações midiáticas cresceram com o sucesso da série americana $E R$ (1994-2009), que durou mais de uma década. Beneficiamo-nos das transcrições do corpus utilizado por Oliveira (2016, p. 44) e concordamos com esta quando assevera que House mantém "mais discursos centrados na área médica, no trato do paciente e de seu quadro de saúde, do que na vida de seus personagens e seus dramas pessoais". Destarte, o foco de nosso trabalho é analisar, qualitativamente, as estratégias de polidez linguística e preservação de face por meio das expressões de modalidade deôntica, como já citado. Acreditamos, assim, que esse corpus pode ser válido para contribuir, ainda, no que se refere à observação dessas estratégias no discurso médico.

Embora o corpus seja de situações enunciativas não espontâneas, consideramo-las produtivas para atender aos interesses deste estudo. Partimos, desse modo, do seguinte pressuposto: os processos de interação entre as personagens são influenciados pelo contexto interacional no qual se encontram e, consequentemente, pelos papéis sociais representados por parte dos personagens. Nesse sentido, analisamos apenas situações de diálogo entre médicosmédicos e médicos-pacientes. Esse recorte se justifica por acreditarmos que as posições dos sujeitos exercem influência em toda forma de interação social e verbal.

Concordamos com Paiva (2008), quando assevera que, para Goffman (1967), a interação social é uma espécie de rito social, ou seja, o falante que participar daquele momento de interação deverá seguir as normas (grau de formalidade, escolhas linguísticas) necessárias, intrínsecas à comunicação. 
Desta forma, esta investigação é de natureza qualitativa e vincula-se ao método de abordagem indutivo-descritivo, declarando que esse estudo teve como base a análise e a descrição de 12 episódios da série House, para, assim, conseguirmos, pela análise dos meios linguísticos, amparar, empiricamente, nossos resultados sobre os verbos modais como estratégias de polidez e preservação de face utilizadas pelos personagens que personificam profissionais da saúde e pacientes.

Os procedimentos para o exame do corpus foram os seguintes: de início, optamos por usar os dados já citados pelo seu contexto interacional. Após a leitura, retiramos as ocorrências que diziam respeito à modalidade deôntica, atentando, apenas, para os valores de permissão e obrigação que fossem marcados por verbos modais. Estabelecemos o tipo de enunciador, fonte, que em nosso caso, poderia ser apenas de primeira ou segunda pessoa; e o alvo, ao qual era dirigido a mensagem. É válido lembrarmos, ainda, que o corpus foi analisado em sua língua original, a inglesa.

Na próxima seção abordamos o percurso de análise e os resultados obtidos.

\section{Exercício analítico e resultados}

Quando analisamos as estratégias de polidez na interação entre médicos-médicos e médicos-pacientes no discurso fictício da série House (2004-2012), optamos por focalizar o exame dos verbos modais de caráter deôntico. Esses dizem respeito às ideias expressas por um meio de expressão linguística (verbos plenos e/ou modais, substantivos, advérbios, adjetivos), que façam uso dos valores de permissão, obrigação e proibição.

A seguir, veremos como os valores de permissão e obrigação revelam as estratégias de polidez em relação ao enunciador, à fonte, aquele que infere uma asserção que, no caso, poderá ser apenas a primeira $\left(1^{\mathrm{a}}\right)$ ou segunda $\left(2^{\mathrm{a}}\right)$ pessoa do discurso, o médico ou o paciente. A numeração entre [] diz respeito ao número do episódio e da temporada, respectivamente:

(01) House: Look, either you're faking, or you've got a pleural effusion that's a build-up of fluid around the lungs which is very serious - and I would have no choice but to stab you in the back with this needle and suck all the fluid out of you. So... (Olha, ou você está fingindo, ou tem uma efusão pleural - que é um aumento de fluído ao redor de seus pulmões, o que é muito sério - e eu não teria escolha a não ser apunhalar você nas costas com essa agulha e sugar todo o fluído de você. Então...). 
Cameron: We should give her a local. (Nós deveríamos dar uma (anestesia) local a ela) - [01X3].

(02) Chase: Maybe we should talk to the kid. (Talvez nós devêssemos falar com a criança).

House: Why, in case he's telling the truth? You're a believer, aren't you? (Para quê, no caso de ele estar falando a verdade? Você é um crente, não é?) $-[01 \mathrm{X} 1]$.

Para Lopes (2009; 2012), o valor de obrigação representa uma necessidade situacional; ou seja, teremos uma ordem que se faz necessária dentro daquele contexto e tempo. Em seu trabalho, a autora constatou que, na sala de aula, o professor seria a fonte deôntica mais recorrente, uma vez que este era a figura de "poder" na sala. Assim, os enunciados relativos aos valores de permissão e obrigação estariam sempre, ou quase sempre, relacionados à sua fala. Em nossa realidade, o ambiente interacional no qual acontece o discurso e o contrato de normas estabelecido por aqueles que fazem parte daquela comunidade classificam o médico como o ser dotado de saber, para com o qual se deve respeito. Em House, os médicos que auxiliam o protagonista esperam dele a última palavra, ou da Dra. Cuddy, a chefe geral de todo o hospital, o que para nós é um traço de preservação da imagem deles, reduzindo o ato ameaçador da face, minimizando a imposição que possam enunciar, enquanto integrantes de uma equipe que possui alguém em um cargo superior, propenso às responsabilidades dos atos de toda a equipe. Essa estratégia indica, ainda, o domínio, por parte dos interlocutores, de regras pragmático-sociais da sistemática da tomada de turno operantes em contextos institucionais como o descrito no excerto em análise. Esse fator, aliás, contribui para a manutenção de uma autoimagem positiva do enunciador, uma vez que ele demonstra respeito aos turnos e à autoridade dos demais coenunciadores envolvidos nessa interação verbal.

Desse modo, em (01) temos a discussão do Dr. House com a sua colega de trabalho; eles investigam que possíveis doenças poderiam ser a causa do problema de sua paciente. Ao portar-se a sua paciente, o Dr. House faz uso de uma ameaça, uma estratégia negativa onrecord de preservação de face, não polida, para induzir o próximo passo do tratamento. Como fonte do enunciado, a sua linguagem é direta e ele não faz uso de expressão mitigadora para amenizar o seu desejo, especialmente, porque os ouvintes, a Dra. Cameron e o paciente, reconhecem o nível hierárquico ao qual pertencem. Lyons (1977) ressalta que é necessário que alguém se reconheça responsável por algo, ou em nosso caso, de fazer algo. 
No trecho (02), o Dr. Chase levanta a hipótese de que talvez fosse a obrigação deles falarem com o paciente. Nesse momento, como se dirige ao seu superior, ele prefere se incluir no discurso, reduzindo o impacto de sua opinião/imposição. Embora não haja sinalização linguística explícita, o contexto comunicativo permite-nos interpretar, pragmaticamente, esse enunciado como um pedido, pois a situação de sua ocorrência confere força ilocucionária impositiva mais branda, cabendo ao alvo aceitar, ou refutar o que foi proposto.

Introduziremos, agora, os excertos (03), (04), e (05), que representam o valor de permissão.

(03) Cameron: You can't diagnose that without a biopsy. (Você não pode diagnosticar isso sem uma biópsia).

House: Yes, we can, we treat it. If she gets better we know that we're right. (Sim, nós podemos, tratámo-la. Se ela ficar melhor sabemos que estamos certos) $-[02 \times 1]$.

(04) Dad: We didn't lie about anything. You, on the other hand, accused us of molesting our son. (Nós não mentimos sobre nada. Você, por outro lado, acusou-nos de molestar nosso filho).

Cuddy: Perfect. (Perfeito).

House: Can we get off my screw-ups and focus on theirs? Theirs is bigger. You're not Dan's parents. (Podemos deixar meus erros e focar nos deles? Os deles são maiores. Vocês não são os pais do Dan).

Mom: We're his parents. (Nós somos os pais dele) - [02X1].

(05) House: Could be, if she didn't already have swollen hilar lymph nodes on the other lung. (Poderia ser, se ela já não estivesse com os nódulos linfáticos hilares inchados no outro pulmão).

Cameron: Could we at least brainstorm for other ideas? [House agrees] Thank you. I still think it could be pneumonia and sarcodosis, but we should check for tuberculosis and definitely rule out congestive heart failure. (Será que poderíamos, pelo menos, discutir outras ideias? [House concorda] Obrigada. Eu ainda acho que poderia ser pneumonia e sarcoidose, mas nós deveríamos checar para tuberculose e definitivamente, descartar insuficiência cardíaca congestiva.) - [01×2].

No primeiro trecho (03), temos a Dra. Cameron negando uma permissão ao Dr. House. Ao utilizar o modal na negativa (can't - não pode), a médica ameaça à face do seu alvo, e o Dr. House não lhe responde com estratégia de polidez, pelo contrário, discorda de sua colega (yes, we can - sim, nós podemos), de modo que, neste exemplo, o verbo modal funciona como uma estratégia de impolidez. Ainda que seja sua subordinada, Dra. Cameron age de forma a lembrá-lo de sua responsabilidade para com o paciente. No entanto, o Dr. House rebate o argumento de Cameron, destacando que, se o paciente melhorar, eles saberão que 


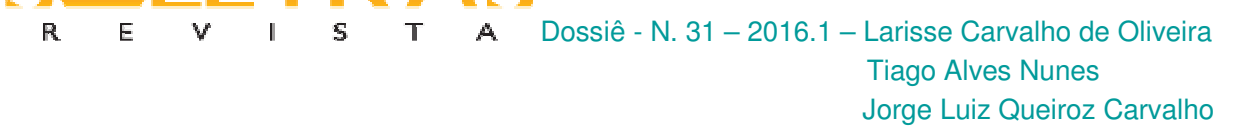

aquele era o tratamento correto. Na série, Cameron é conhecida por sua ética no trabalho e seu respeito para com os pacientes, o que a faz preservar positivamente a face de toda a equipe médica, por meio de seu "confronto" com Dr. House, ao mesmo tempo em que se expõe, pondo sua face mais “à mostra”. Dr. House, por usa vez, mantém-se distante dos pacientes o máximo possível, usando os membros de sua equipe para fazer o intermédio necessário ao tratamento.

Em (04) temos uma das poucas ocorrências em que Dr. House pede permissão para algo. Nesse ponto, ele requer que a Dra. Cuddy, chefe do hospital, leve em consideração o erro dos pais de seu paciente, que o levou a tratamentos errôneos devido às informações fornecidas sobre o histórico familiar do paciente. Embora se reportando à sua superior, House faz uso de um modal/auxiliar informal, 'can' (poder), desrespeitando a autoridade da Dra. Cuddy. Todavia, apesar do comportamento do Dr. House, seu grau de "preocupação" com o que poderia ter acontecido ao paciente parece minimizar a sua falta, preservando, assim, sua face e desviando a atenção de sua escolha linguística. Desse modo, para preservar sua face, manter a imagem de médico competente e não mostrar inferioridade diante do paciente, Dr. House se dirige à chefe do hospital de forma provocadora, fazendo uso de um verbo modal que indica um pedido de permissão, tomando o turno, que ainda não havia sido notado pela Dra. Cuddy.

Por sua vez, no trecho (05), podemos notar que a Dra. Cameron, respeitando o poder de House, utiliza o modal/auxiliar 'could' (poder) para pedir-lhe permissão. Além de tal valor, empregado em seu discurso, a médica traz argumentos para sustentar sua postura. Há, ainda, mais dois casos deônticos, 'should' (dever) e 'rule out' (descartar); esses representam uma obrigação de ambos, House e Cameron, como médicos a buscar a verdadeira causa da enfermidade de seus pacientes. A forma 'should' é um modal/auxiliar que geralmente é usado quando o enunciador deseja dar um conselho, ou indicar responsabilidade para algo/alguém. De acordo com Tenuta, Oliveira e Orfanó (2012), o verbo modal 'should', em sua forma negativa, "indica necessidade de se mudar uma realidade de acordo com as expectativas ou exigências do escritor", em nosso caso, do médico. Os efeitos de sentido provocados a partir desses modais, assim, indicam que a personagem busca preservar sua face, mostrando respeito, sugestões, possíveis soluções para o caso e revelando a capacidade da médica de 
dialogar de forma polida com alguém que detém um poder de influência maior, a saber, Dr. House.

Como pondera Vihla (1999), o verbo modal 'should' também pode expressar uma obrigação, ou uma regra a ser seguida:

$(69)^{5}$ If the development of VF is observed in a monitored patient, an initial counter shock of 200 to 300 joules should be given immediately. (Rogers, HB) [Se o desenvolvimento da fibrilação ventricular (VF) é observado em um paciente monitorado, um choque inicial de 200 a 300 joules deve ser administrado imediatamente].

A autora constatou em seu estudo que a modalidade deôntica é, em suma, empregada para indicar uma necessidade modal, ou para apontar normas da profissão. Sendo o uso daquela importante para indicar um discurso, o médico, governado por regras de conduta.

Quando a Dra. Cameron opta por incluir-se no discurso (we should check...), ela emite certo grau subjetivo que condiz com suas expectativas, enquanto participante daquela sociedade e como senhora de um amplo conhecimento profissional, o que, no entanto, não parece ser suficiente para o Dr. House. O verbo 'rule out' aparece em sua forma imperativa, reforçando a necessidade do requerido ser posto em prática.

Por sua vez, a escolha da Dra. Cameron por verbos modais pode se encaixar na realização de estratégias on-record de polidez, pois tornando o seu discurso mais formal, a médica se manifesta de modo não agressivo, preservando a sua face. É como se, por meio dessa escolha linguística, o enunciador mitigasse a força ilocucionária do que foi expresso. Já na visão de Paiva (2008, p. 50), "o pedido é uma alternativa frequentemente usada pelos falantes para minimizar a imposição de um ato de fala, que, por sua vez, gera uma ameaça à face negativa do ouvinte". Na língua inglesa é possível usar-se tanto can quanto could para pedidos, no entanto, a última forma é mais polida que a primeira.

As manifestações envolvendo pacientes como fonte do enunciado foram mínimas. Como explica Oliveira (2016, p. 61), "quando um paciente se porta ao seu médico, isso geralmente acontece de modo formal, requerendo o uso de meios linguísticos que amenizem a carga imposta ao ouvinte, o médico". Assim, o processo de preservação de face é mais perceptível quando em relação às interações entre os personagens médicos da série.

Observemos, agora, o excerto 06:

5 A numeração desse exemplo segue a ordem utilizada por Vihla (1999, p. 64). 
(06) House: His heart rate's a little high. (A frequência cardíaca dele está um pouco alta).

Arlene: Should I be worried? (Eu deveria ficar preocupada?)

House: Probably just means he's still in discomfort from the surgery. I'm going to up his morphine a little. (Provavelmente isso apenas significa que ele ainda está em desconforto por causa da cirurgia. Eu vou elevar a morfina dele um pouco) - [01X3].

O trecho (06) mostra a parente de um paciente como a fonte do enunciado, indagando se deveria ficar preocupada. Em tal situação, a fonte traz para si a responsabilidade para com o paciente, uma obrigação interna, imposta por ela mesma. Como o seu alvo é um médico, ela age com polidez ao usar o verbo modal should (dever) a fim de preservar sua face, neste contexto enunciativo. A polidez reside no fato de ela fazer uma indagação, perguntando, através do modalizador, como deveria agir diante do caso de frequência cardíaca alterada, indicando sua submissão às decisões do médico. Desta forma, Arlene demonstra respeito e marca a autoridade de seu alvo, agindo como se estivesse em débito para com ele, preservando sua face de modo a não demonstrar arrogância nem hostilidade diante de um de seus superiores, mas respeitando a autoridade exercida por Dr. House. Tal estratégia evita proximidade, intimidade desnecessária que possa aviltar a face dos participantes da interação.

\section{Considerações finais}

Este estudo focalizou como a modalidade deôntica funciona como estratégia de polidez linguística e preservação de faces no discurso médico-médico e médico-paciente nas interações da série americana House (2004-2012). Interessou-nos demonstrar em que medida os verbos modais são convocados nos eventos comunicativos para, ao mesmo tempo, funcionar como estratégia de (im)polidez e preservação de faces e, às vezes, como ameaça à face do coenunciador.

Num primeiro momento, fizemos algumas considerações sobre os principais conceitos de polidez linguística e preservação de face, orientados pelos escritos de Brown e Levinson (1987), bem como Goffman (1967); em seguida, conceituamos modalidade deôntica, atentando para o pressuposto de que os verbos modais podem funcionar como estratégia de (im)polidez linguística e preservação de faces nas interações médico-médico e médico- 


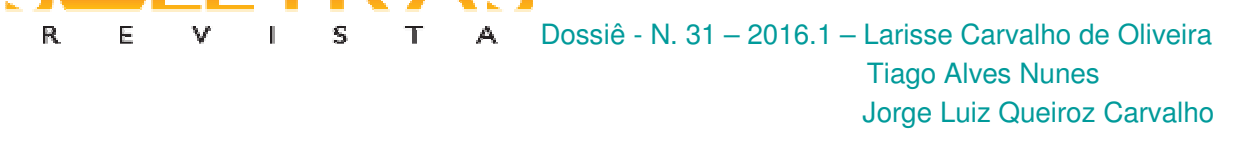

paciente. Para tanto, utilizamo-nos do corpus produzido por Oliveira (2016), quem coletou e tabulou as ocorrências modais deônticas da série citada.

House faz parte do gênero série televisiva, centrando-se em um drama médico, no qual a personagem principal é a enfermidade, que a cada episódio deve ser desvendada, como se fosse um crime, ao estilo sherlockiano. As interações na série, neste estudo, funcionaram como modo de acesso às estratégias de polidez e preservação de faces, de sorte que as utilizamos para inferir, após as análises, como os verbos modais foram utilizados nesse tipo de estratégia linguístico-discursiva.

Após análise das ocorrências, os resultados comprovaram que o uso da categoria gramatical modalidade, sob a expressão dos verbos modais deônticos, colabora para a preservação da face dos personagens médicos, bem como lhes serve como estratégia de (im)polidez linguística. Em suma, por um lado, aqueles que estavam sob o julgo do Dr. House optaram por se incluir como alvo de seus enunciados para preservar e, desta forma, ameaçar a face do outro. Por outro lado, a personagem Dr. House, responsável pela decisão final nos casos, fez uso de estratégias de preservação on-record negativa, não minimizando a força ilocucionária de seus enunciados. O meio de expressão que analisamos, os verbos modais, tem valor polissêmico e, na língua inglesa, pode inferir maior/menor polidez, ou seja, um maior ou menor grau de envolvimento com o dito, dependendo daquele que seja escolhido.

Com este trabalho, assim, esperamos ter contribuído com os estudos pragmáticos, especialmente para as questões que envolvem a (im)polidez linguística, bem como para a preservação de faces. Almejamos ter dado uma contribuição, também, aos trabalhos relacionados à modalidade, em especial a deôntica, que se preocupa em mostrar como os verbos modais podem contribuir à preservação, à manutenção e à ameaça à face. Com o subsídio desse trabalho, esperamos ter oferecido mais uma reflexão sobre as intersecções que podem ser feitas entre esses dois conceitos que, acreditamos, podem ser relacionados em outros estudos para evidenciar funções vinculadas à modalidade deôntica que têm sido pouco abordadas na literatura e marcadores linguístico-discursivos que materializam as estratégias de preservação de face e da (im)polidez.

\section{Referências}


BROWN, P.; LEVINSON, S. Politeness: some universals in language usage. Cambridge: Cambridge University Press, 1987.

CERVONI, J. A enunciação. São Paulo: Ática, 1989.

MONTE-FILHA, M.V.M; LOPES, M.F.S; OLIVEIRA, L.C. A variação entre verbos modais e verbos plenos no discurso médico televisivo - House m.d. In: Anais da XXV Jornada Nacional do GELNE. Natal, RN : EDUFRN, 2014. p.695-705.

GOFFMAN, E. Interaction ritual: essays on face-to-face behavior. Garden City: Anchor Doubleday, 1967.

KOCH, I.G.V. Argumentação e linguagem. 9. ed. São Paulo: Cortez, 2004.

LOPES, M.F.V. A modalidade deôntica na aula de inglês ministrada em português. 2009. 263f. Tese (Doutorado em Linguística) - Centro de Humanidades, Universidade Federal do Ceará, Fortaleza, 2009.

Gramática de significados. Fortaleza: Edições UFC, 2012.

LYONS, J. Semantics. Cambridge: Cambridge University Press, 1977.

OLIVEIRA, L. C. A modalidade deôntica em discurso profissional na mídia televisiva. 2016. 141f. Dissertação (Mestrado em Linguística) - Centro de Humanidades, Universidade Federal do Ceará, Fortaleza, 2016.

O estudo da modalidade no gênero série televisiva: um auxílio ao ensino de língua estrangeira. In: Anais da XXV Jornada Nacional do GELNE, Natal: EDUFRN, 2014.

PAIVA, G.M.F. A polidez linguística em sala de bate-papo na internet. 2008. 294f. Dissertação (Mestrado em Linguística) - Centro de Humanidades, Universidade Federal do Ceará, Fortaleza, 2008.

SHORE, D. House M. D. Fox / Universal Studios. Criador: David Shore. Produção: Katie Jacobs, David Shore, Paul Attanasio, Bryan Singer, Russel Friend, Garrett Lerner e Thomas L. Moan - Fox. Elenco: Hugh Laurie, Lisa Edelstein, Robert Sean Leonard, Jennifer Morrison, Jesse Spencer, Omar Epps, Petter Jacobson, Kal Penn, Olivia Wilde. Script disponível em: http://clinic-duty.livejournal.com/12225.html. Acessado em: 10 Março de 2016.

TENUTA, A.M; OLIVEIRA, A.L.A.M.; ORFANÓ, B.M. How Brazilian learners express modality in their writing: a corpus-based study on lexical bundles. In: Revista Intercâmbio. São Paulo, v. 26, p. 1-15, 2012.

http://revistas.pucsp.br/index.php/intercambio/article/download/15173/11314. Acessado em 20 de junho de 2015. 


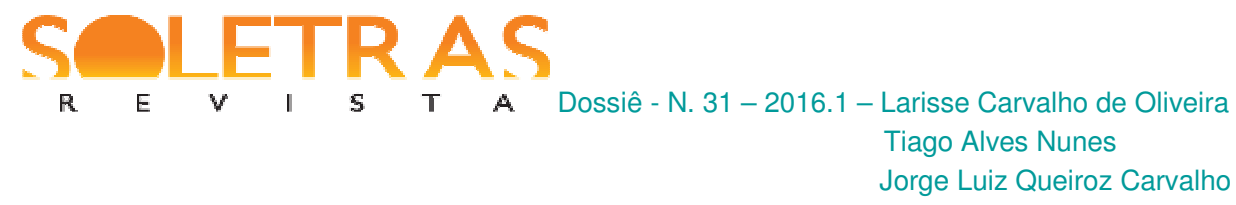

VIHLA, M. Medical writing: modality in focus. Amsterdã; Atlanta, GA: Editions Rodopi B. $\mathrm{V}, 1999$.

\title{
Modal verbs as linguistic-discursive strategy of linguistic (im)politeness and face preservation in doctor-doctor interactions and doctor-patient from the House series
}

\begin{abstract}
Linguistic Politeness anchors the construction, maintenance and face preservation of the speakers, so that the monitoring of communicative event production is paramount in these processes. The objective of this study is to analyze the strategies of (im)politeness and face preservation in dialogues between doctors and patients characters from the television series House (2004-2012), paying attention to the fact that such strategies are part of the discursive construction of typical linguistic artifacts of this profession. As theoretical basis, it was used the studies of Brown and Levinson (1987), Goffman (1967) and Paiva (2008) regarding the concepts of positive and negative politeness and face preservation. Firstly, twelve episodes of the aforementioned series were chosen, the scripts were collected from the web and their transcription was checked with the audio. Afterwards, the dialogues that had interactions among patients and doctors were separated to assess how modal verbs could cooperate or not, in the process of politeness and preservation of image/face of their interlocutors. The cases analyzed showed that the physicians participating in Dr. House's team sought to preserve their face through the use of modal verbs, and the inclusion of their figures in the statements. As a mitigating factor of responsibility, or to decrease the illocutionary force of their speech acts, such professionals acted as source and target of their statements. Therefore, we can conclude that the use of such verbs enable the reduction of the weight of responsibility and threatening acts of face in social interactions represented by the series.
\end{abstract}

Keywords: Interaction. Face Preservation. Linguistic Politeness. Modality.

Recebido em: 20 de março de 2016.

Aprovado em: 13 de julho de 2016. 